\title{
ISOLATION, PURIFICATION, AND CHARACTERIZATION OF BOVINE TENDON COLLAGEN AND ANALYSIS OF GLYCINE, PROLINE, AND HYDROXYPROLINE BY HIGH-PERFORMANCE LIQUID CHROMATOGRAPHY-FLUORESCENCE
}

\author{
DWI YULIANTI, HARMITA*, TAUFIQ INDRA RUKMANA
}

Department of Pharmacy, Faculty of Pharmacy, Universitas Indonesia, Depok 16424, Indonesia. Email: igakadeharmita@gmail.com

Received: 01 June 2018, Revised and Accepted: 11 November 2018

\section{ABSTRACT}

Objective: In this study, collagen isolated from bovine tendon was purified and characterized, and the optimum conditions for analysis of glycine, proline, and hydroxyproline were determined.

Methods: The collagen isolation process used $0.1 \mathrm{~N} \mathrm{NaOH}$ as a pretreatment, $0.5 \mathrm{M}$ acetic acid in the extraction, $0.9 \mathrm{M} \mathrm{NaCl}$ in the salting-out step, centrifugation and dialysis for purification, and freeze-drying as the final step. The characterization of the collagen included analysis of the organoleptic properties, $\mathrm{pH}$, moisture content, viscosity, and ash content. A Fourier-transform infrared (FTIR) spectroscopy analysis and Casson's trichrome staining were also performed. The collagen was hydrolyzed in $6 \mathrm{~N} \mathrm{HCl}$ for $24 \mathrm{~h}$ and derivatized using 9-fluorenylmethoxycarbonyl chloride. The optimum condition was conducted from the optimal wavelength, selection of mobile phase composition, and flow rate.

Results: The average content was $11.867 \pm 0.20 \%$ for glycine, $33.247 \pm 0.20 \%$ for proline, and $10.51 \pm 0.23 \%$ for hydroxyproline. The optimum condition analysis for collagen was achieved by high-performance liquid chromatography (HPLC) with a C18 ${ }^{\circledR}$ column and a fluorescence detector (excitation: $265 \mathrm{~nm}$ and emission: $320 \mathrm{~nm}$ ) with mobile phase acetate buffer ( $\mathrm{pH} 4.2$ ):acetonitrile (55:45), and the flow rate was $0.8 \mathrm{~mL} / \mathrm{min}$.

Conclusion: The collagen isolated from bovine tendon was obtained at a yield of $0.690 \%$, and the identity was confirmed by FTIR functional group analysis and Casson's trichrome staining. The HPLC conditions using a fluorescence detector for analysis of glycine, proline, and hydroxyproline concentrations in the bovine tendon collagen were optimized. The analysis of amino acids gave the average levels of $33.247 \pm 0.20 \%$ for glycine, $11.867 \pm 0.20 \%$ for proline, and $10.51 \pm 0.23 \%$ for hydroxyproline.

Keywords: Amino acid, Bovine tendon collagen, Content, Derivatization, Fluorescence, Glycine, High-performance liquid chromatographic, Hydroxyproline, Optimization, Proline.

(c) 2018 The Authors. Published by Innovare Academic Sciences Pvt Ltd. This is an open access article under the CC BY license (http://creativecommons. org/licenses/by/4. 0/) DOI: http://dx.doi.org/10.22159/ijap.2018.v10s1.69

\section{INTRODUCTION}

Collagen is a fibrous protein located in the extracellular space and in various connective tissues that account for nearly $30 \%$ of the total protein in vertebrate and invertebrate organ tissues [1]. The main sources of collagen are skin tissue, tendons, cartilage, and bones. Collagen is indispensable as a raw material in the food, cosmetics, and biomaterials industries, especially those in the health field [2]. With developments in technology, the collagen can be used to repair bone tissue because the protein is able to stimulate the growth of new bone cells. Judging from its benefits and uses, collagen has an important role for humans, especially in the health field, so the demand and interest in collagen use are expected to increase. The production of collagen in Indonesia is still not optimal. In 2003, Indonesia imported $>6200$ tons of collagen at approximately US $\$ 1 / \mathrm{g}$ [3]. Collagen can be produced by isolation from bovine tendon, which is a particularly good source [2]. One-third of the protein mass of bovines is collagen, and the tendons have a fairly high content of $85 \%$. In Indonesia, the need for beef is increasing; beef production from 2015 to 2016 was increased from 506.661 tons to 524.109 tons. Therefore, due to increasing cattle production, there have been several studies on collagen isolation from cow body parts, such as tendons. In this study, collagen isolated from bovine tendon was purified and characterized, and the optimum conditions for analysis of glycine, proline, and hydroxyproline were determined.

\section{MATERIALS AND METHODS}

Materials

Brahman cross bovine tendon obtained from the Tapos Animal Slaughterhouse, Depok, undenatured type II collagen (Inter Health,
Nutraceuticals Incorporated), trans-4-hydroxy-L-proline (SigmaAldrich), standard amino acid L-proline (Sigma-Aldrich), standard glycine amino acid (Sigma-Aldrich), Masson's trichrome stain (Pusat Studi Satwa Primata IPB; Pathology Laboratory), 9-fluorenylmethoxycarbonyl chloride (FMOC-Cl) (Hangzhou Dingyan Chem. Co), boric acid (Merck), high-performance liquid chromatographic (HPLC) grade acetonitrile (Merck), HPLC grade methanol (Merck), sodium hydroxide (Merck), sodium $\mathrm{Cl}$ (Merck), hydrochloric acid (Merck), aquadest (Brataco), sodium acetate (Merck), glacial acetic acid (Merck), and $\mathrm{KBr}$ (Merck).

\section{Overview of methods}

The isolation and purification of collagen from bovine tendon were performed using the method of Lestari with modifications [4]. The process of isolation began with a pre-treatment step using $0.1 \mathrm{~N} \mathrm{NaOH}$, extraction with $0.5 \mathrm{~N}$ acetic acid, precipitation using $0.9 \mathrm{~N} \mathrm{NaCl}$, centrifugation and dialysis for purification, and lyophilization (freezedrying) to obtain solid collagen. The following parameters of the isolated collagen were analyzed: Organoleptic properties, $\mathrm{pH}$, moisture content, ash content, viscosity, and functional groups determined by Fourier-transform infrared (FTIR) spectroscopy. To confirm the presence of collagen in the isolated samples, Casson's trichrome staining was conducted.

After obtaining the collagen, a quantitative analysis was performed. An amino acid analysis was performed by HPLC with fluorescence detection. Beforehand, collagen needs to be derivatized with fluorogenic reagents to form fluorescent compounds because collagen does not have chromophores that absorb ultraviolet/visible light. 
In this study, $\mathrm{FMOC}-\mathrm{Cl}$, a reagent that can react with primary and secondary amino acids was selected to form a fluorescent derivative required in the optimization of a selective and sensitive HPLC method for determination of the content of glycine, as a primary amino acid, and that of proline and hydroxyproline, as secondary amino acids, in isolated bovine tendon collagen.

\section{Instrument}

For HPLC, we used HPLC pumps (LC 20AT Solvent Delivery System; Shimadzu, Japan), a YMC-Triart ${ }^{\circledR}$ C18 column, a RF 20A fluorescence detector (Shimadzu), manual injectors, and data processors (LC Solution Software). We also used syringe HPLC (SGE, Australia), ultraviolet-visible (UV-Vis) spectrophotometer (UV-1601; Shimadzu), FTIR-8400S equipped with DRS-8000 (Shimadzu), LC 20/H ultrasonic cleaner (Elma), $\mathrm{pH}$ meters (pH 510; Eutech Instruments), freeze dryer (Eyela FDU 1200), centrifuges (NF 400R), vortex mixer (Wisemix VM-10), oven (Cole Parmer, Chemoscience), dialysis tubing cellulose membrane (12 kDa, diameter $49 \mathrm{~mm}$; Sigma-Aldrich), Ostwald viscometer (Schott-Gerate), Millipore 0.45 - $\mu \mathrm{m}$ filter membranes, filter paper no. \#40 (Whatman), and analytical balance.

\section{Preparation of collagen standard solution}

The collagen standard solution was prepared by weighing $50 \mathrm{mg}$ of the standard collagen, which was then dissolved in $5 \mathrm{~mL}$ of $6 \mathrm{~N} \mathrm{HCl}$ to be hydrolyzed in a $110^{\circ} \mathrm{C}$ oven 4 times $(22,23,24$, and $25 \mathrm{~h})$. The solution was then dissolved in acetic buffer ( $\mathrm{pH} 4.20)$ and diluted to a concentration of $10 \mu \mathrm{g} / \mathrm{mL}$.

\section{Preparation of amino acid stock solutions}

A 3.8-mM hydroxyproline stock solution was prepared by dissolving $50 \mathrm{mg}$ of hydroxyproline in $100 \mathrm{~mL}$ of $0.1 \mathrm{~N} \mathrm{HCl}$. A proline stock solution of $4.34 \mathrm{mM}$ was prepared by dissolving $50 \mathrm{mg}$ of proline in $100 \mathrm{~mL}$ of $0.1 \mathrm{~N} \mathrm{HCl}$. A $6.66 \mathrm{mM}$ glycine stock solution was prepared by dissolving $50 \mathrm{mg}$ of glycine in $100 \mathrm{~mL}$ of $0.1 \mathrm{~N} \mathrm{HCl}$. Each solution was diluted to a concentration of $10 \mu \mathrm{g} / \mathrm{mL}$.

\section{Preparation of FMOC-Cl solution}

A solution of $15 \mathrm{mM}$ FMOC-Cl was prepared by weighing $39 \mathrm{mg}$ of FMOC-Cl (BM $258.7 \mathrm{~g} / \mathrm{mol}$ ) that was then diluted it with $10 \mathrm{~mL}$ of acetonitrile to a concentration of $1.5 \mathrm{mM}$.

\section{Preparation of acetate buffer solution}

A $15 \mathrm{mM}$ acetate buffer was prepared by dissolving $1.6 \mathrm{~g}$ of anhydrous sodium acetate in $400 \mathrm{~mL}$ of aquadest. The $\mathrm{pH}$ was adjusted to 4.2 with glacial acetic acid P. The acetate buffer was then filtered through a Whatman no. 45 filter.

\section{Preparation of boric buffer solution}

A $100 \mathrm{mM}$ boric buffer was prepared by dissolving $0.0618 \mathrm{~g}$ of boric acid (MW $61.85 \mathrm{~g} / \mathrm{mol}$ ), in $100 \mathrm{~mL}$ of Aquabidest. Then, the buffer was diluted to $10 \mathrm{mM}$ and the $\mathrm{pH}$ was adjusted to $\mathrm{pH} 9$ by dropwise addition of $6 \mathrm{~N} \mathrm{NaOH}$.

\section{Isolation of collagen from bovine tendon}

The bovine tendon was washed thoroughly, cut into $1-\mathrm{cm}$ pieces, and then weighed to give approximately $1000 \mathrm{~g}$ portions. The bovine tendon slices (samples) were immersed in $0.1 \mathrm{~N} \mathrm{NaOH}$ at a ratio of 1:5 for 3 days; the $0.1 \mathrm{~N} \mathrm{NaOH}$ solvent was replaced every day.

The extraction process in $0.5 \mathrm{M}$ acetic acid was performed over 3 days. After the extraction process was completed, the extracted filtrate was collected as filtrate 1 . The residue from the sample was then extracted again using a new $0.5 \mathrm{M}$ acetic acid solution for 3 days, and the extracted filtrate was collected as filtrate 2. Filtrates 1 and 2 were mixed for further purification by salting-out using $\mathrm{NaCl}$ until the final concentration reached $0.9 \mathrm{~N}$ from the extract volume. White clouds of collagen formed and floated in the acid extract. The acid extract was then centrifuged at $4000 \mathrm{rpm}$ and $4^{\circ} \mathrm{C}$ for 20 min to precipitate the collagen.
Dialysis was performed by immersing a collagen-containing sac with $0.1 \mathrm{M}$ acetic acid at a ratio of 1:10 of the volume of collagen solution for 1 day. The $0.1 \mathrm{M}$ acetic acid was then replaced with aquadest. The $\mathrm{pH}$ of the new aquadest was adjusted for dialysis to $\geq 5$. The dialysis was performed at a temperature of $<20^{\circ} \mathrm{C}$ or placed in a refrigerator. The collagen obtained from the dialysis process was placed in a container for lyophilization (freeze-drying) to collect it in the solid form. The whole process was performed at a low temperature $\left(4^{\circ} \mathrm{C}\right)$.

\section{Characterization of the bovine tendon collagen Organoleptic properties}

The organoleptic test was performed by looking at the physical appearance, color, and smell of the collagen isolated from the Brahman cross bovine tendon.

\section{Functional group analysis by FTIR}

First, $200 \mathrm{mg} \mathrm{KBr}$ and $2 \mathrm{mg}$ standard collagen were mixed and crushed to give a homogeneous powder and then inserted into a DRS-8000 device (non-disc). The spectrum was acquired from 400 to $4000 \mathrm{~cm}^{-1}$ wave numbers. All collagen samples were treated equally to obtain the IR spectra.

\section{Casson's trichrome/Masson's trichrome staining}

An approximate $0.1-\mu \mathrm{L}$ sample of collagen from the bovine tendon isolation was placed in a glass object and allowed to air-dry. Then, the sample was soaked in Casson's trichrome solution for 5 min, washed with running water for 3-5 s, and dried by absorption with filter paper until dry. Fast dehydration was achieved by mixing the sample with $100 \%$ alcohol 3 times. The collagen tissue observation was performed using a light microscope with a $10 \times$ objective magnification. A positive result for the presence of collagen was characterized by the color of the sample turned blue.

\section{pH values}

A total of $1 \mathrm{~g}$ of sample was dissolved in $70 \mathrm{~mL}$ of aquadest until homogeneous. The $\mathrm{pH}$ meter was turned on and then calibrated by allowing the readings to stabilize at each $\mathrm{pH}$. The electrode was dipped into the sample solution until a stable $\mathrm{pH}$ value was obtained [5].

\section{Measurement of the water content}

A glass weighing bottle was dried in an oven at $105^{\circ} \mathrm{C}$ for $1 \mathrm{~h}$. Then, the dried glass weighing bottle was placed in a desiccator for $15 \mathrm{~min}$ and weighed. A $1 \mathrm{~g}$ sample was then added to the dry glass weighing bottle and weighed. The glass weighing bottle containing the sample was placed into an oven at $105^{\circ} \mathrm{C}$ for $5-6$ min or until it reached a constant weight. The glass weighing bottle was placed into a desiccator for $30 \mathrm{~min}$ and then weighed [5].

\section{Measurement of the ash content}

A porcelain cup was cleaned and then dried in an oven at $105^{\circ} \mathrm{C}$ for $30 \mathrm{~min}$. The cup was then placed in a desiccator for $30 \mathrm{~min}$ and weighed. $\mathrm{A} 1 \mathrm{~g}$ sample was added to the porcelain cup, and the cup with the sample was placed in a furnace at $600^{\circ} \mathrm{C}$ for $7 \mathrm{~h}$. The cup containing the residual ash was placed in a desiccator for $30 \mathrm{~min}$ and then weighed to obtain the weight of the ash residue [5].

\section{Viscosity test}

The viscosity test was performed by preparing a solution of collagen sample at a concentration of $0.5 \%$ in aquadest, followed by measurement of the viscosity using an Ostwald viscometer. The solution was passed through the capillaries from the upper limit to the bottom, and the flow time was accurately recorded (stopwatch). The value of the viscosity was expressed in units of centipoises (cP).

\section{Amino acid derivatization process}

A $300-\mu \mathrm{L}$ test solution was taken for the derivatization process by adding $300 \mu \mathrm{L}$ of $10 \mathrm{mM}$ boric buffer ( $\mathrm{pH}$ 9) to $300 \mu \mathrm{L}$ of 
$1.5 \mathrm{mM}$ FMOC-Cl (in acetonitrile). Then, $20 \mu \mathrm{L}$ of the sample was injected into the HPLC.

Optimization of the HPLC conditions for analysis of glycine, proline, and hydroxyproline

Determination of the optimal analysis wavelengths

In this step, the determination of the optimal emission wavelengths was performed. The determination of the excitation wavelength was performed using a UV-Vis spectrophotometer and standard solutions of hydroxyproline, glycine, and proline.

\section{Selection of mobile phase composition}

To select the mobile phase composition, several acetate buffer (pH 4.2):acetonitrile ratios were investigated as follows: 55:45, 60:40, and 65:35.

\section{Selection of the mobile phase flow rate for analysis}

The mobile phase flow rates (at the compositions described above) of $0.8,1.0$, and $1.2 \mathrm{~mL} / \mathrm{min}$ were investigated.

\section{Test system compatibility}

A 300- $\mu \mathrm{L}$ aliquot of collagen standard solution was added to $300 \mu \mathrm{L}$ of $10 \mathrm{mM}$ boric buffer, $\mathrm{pH}$ 9, and then $300 \mu \mathrm{L}$ of $1.5 \mathrm{mM}$ FMOC-Cl (in acetonitrile) was added. After the derivatization, $20 \mu \mathrm{L}$ of the sample was injected into the HPLC using the test mobile phases and selected flow rates. Six injections were made.

\section{Calibration curve and linearity test}

Each standard solution of glycine, proline, and hydroxyproline in different concentrations was injected into the HPLC at the selected conditions.

\section{Determination of the limit of detection (LOD) and limit of quantitation (LOQ)}

From the obtained calibration curve, the smallest detectable concentration (LOD) and smallest detectable quantitative concentration (LOQ) were calculated from the linear regression line of the calibration curve.

Determination of glycine, proline, and hydroxyproline concentrations in isolated collagen samples from bovine tendon $50 \mathrm{mg}$ of collagen isolated from the bovine tendon was placed in a suitable container and mixed with $5 \mathrm{~mL}$ of $\mathrm{HCl} 6 \mathrm{~N}$. The mixture was incubated in an oven at $110^{\circ} \mathrm{C}$ for $22,23,24$, and $25 \mathrm{~h}$, then cooled, and dissolved in acetate buffer to obtain a concentration of $10 \mu \mathrm{g} / \mathrm{mL}$.

The derivatization was then performed in the same manner as that used for the standard preparation. A $20-\mu \mathrm{L}$ aliquot of each sample solution was injected into the HPLC under the selected analysis condition. Three replicates of each sample were injected to obtain an average value.

\section{RESULTS AND DISCUSSION}

\section{Isolation of collagen}

The result of the bovine tendon that was immersed in the $0.1 \mathrm{~N} \mathrm{NaOH}$ solution was turned a cloudy color on the $1^{\text {st }} d a y$, but on the $2^{\text {nd }}$ and $3^{\text {rd }}$ days, the solution became clearer. This finding indicates that the dirt on the bovine tendon on the $2^{\text {nd }}$ and $3^{\text {rd }}$ days was reduced.

After the extraction process, the weight of the bovine tendon increased as it absorbed the acetic acid solution, and its shape changed to a more developed and elastic-like jelly. Then, the separated acid filtrate was subjected to the salting-out process or to the addition of $\mathrm{NaCl}$. $\mathrm{NaCl}$ binds the acetic acid, so the collagen contained in the filtrate precipitated. The salted-out collagen was separated by centrifugation at $4000 \mathrm{rpm}$ and $4^{\circ} \mathrm{C}$ for $20 \mathrm{~min}$, which allowed large collagen pieces to settle on the bottom of the centrifugation tubes.
The process of dialysis for purification began by passing $0.1 \mathrm{M}$ acetic acid over the collagen, so the concentration of $0.5 \mathrm{M}$ acetic acid dissolved in the collagen decreased. The ratio of the volume of liquid collagen and $0.1 \mathrm{M}$ acetic acid was 1:5. The dialysis process was continued by passing it over the aquadest that served to dissolve the $\mathrm{NaCl}$ and raise the $\mathrm{pH}$ of the collagen to eliminate acid.

After the dialysis process was complete, the wet collagen was lyophilized using a freeze dryer so that we could obtain solid collagen in the form of fine fibers. The total weight of the dry collagen obtained was $7.273 \mathrm{~g}$, so the yield of the bovine collagen sample was $0.690 \%$.

\section{Characterization of bovine tendon collagen} Organoleptic properties

The collagen obtained from the isolation was in a dry, filamentous, white, solid form (Fig. 1). The fishy odor produced by it was the result of the isolation from bovine tendon, and the acidic odor was caused by the isolation process using acetic acid.

\section{Functional group analysis by FTIR}

The FTIR spectroscopy for both the standard collagen and sample showed a typical absorption spectrum of collagen, i.e., absorption peaks in the amide uptake region of amides A, B, I, II, and III. The amide $\mathrm{A}$ in collagen shows asymmetrical stretching of $\mathrm{NH}$ with hydrogen bonds detected in the approximate range of $3200-3440 \mathrm{~cm}^{-1}$ (Sai and Babu, 2001). Amide B uptake shows the $\mathrm{CH}_{2}$ asymmetric stretch of collagen in the range of $2935-2915 \mathrm{~cm}^{-1}$. The amide I C=0 stretch was observed at $1681.02 \mathrm{~cm}^{-1}$ and the absorption region was in the range of $1600-1690 \mathrm{~cm}^{-1}$ [6]. The amide II bands are for CN stretching and $\mathrm{NH}$ bending. The amide II spectra occurred in the absorption region of $1480-1575 \mathrm{~cm}^{-1}$ and the center was at $1553.71 \mathrm{~cm}^{-1}$. The $\mathrm{CH}_{2}$ bend region of amide II was found at $1450.52 \mathrm{~cm}^{-1}$ [6]. The amide III NH bending of the $\mathrm{NH}$ bound to the $\mathrm{CN}$ group was located in the region of $1229-1301 \mathrm{~cm}^{-1}$. The amide III in the collagen samples was observed at a wave number of $1234.48 \mathrm{~cm}^{-1}$.

\section{Staining with Casson's trichrome}

The collagen isolation from the bovine tendon showed a positive result of collagen tissue with the presence of blue color (Fig. 2). The blue color indicates the presence of collagen tissue derived from aniline blue stain.

\section{pH value}

The $\mathrm{pH}$ of the collagen samples was 6.64. The collagen $\mathrm{pH}$ value in this study was in accordance with the collagen standard established by BSN (2014), which states that the standard $\mathrm{pH}$ value of collagen ranges from 6.5 to 8 . The neutral $\mathrm{pH}$ of the collagen samples obtained is due to the effect of neutralization with aquadest after dialysis using acetic acid [7].

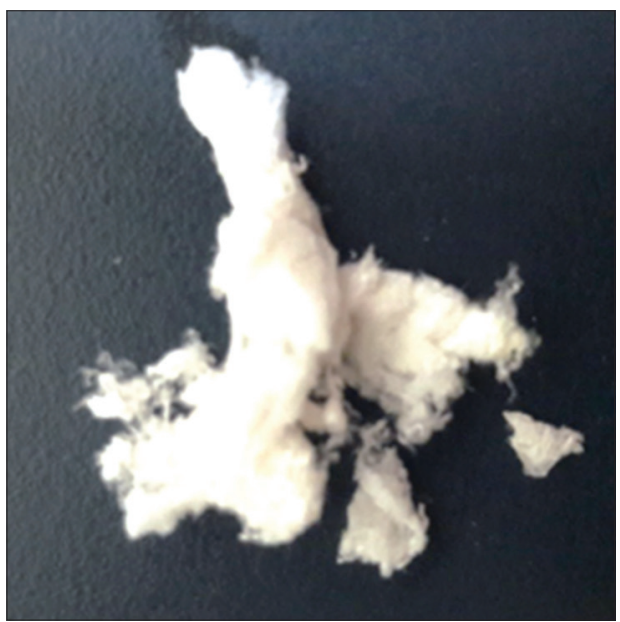

Fig. 1. Organoleptic isolated bovine collagen 


\section{Water content}

The water content values obtained from two measurements were $1.80 \%$ and $1.70 \%$, with an average moisture content of $1.75 \%$, which met the collagen quality requirement based on BSN (2014) $(\leq 12 \%)$. Samples that have high water contents can be damaged if left in open air because of microbial activity [7].

\section{Ash content}

The ash content values obtained from two measurements were $0.20 \%$ and $0.30 \%$, with an average of $0.25 \%$, which met the quality requirement of collagen based on BSN (2014) (s1.0) [7].

\section{Viscosity test}

The viscosity values of the collagen samples were $0.702,0.731$, and $0.726 \mathrm{cP}$, with an average of $0.720 \mathrm{cP}$, which was low because the collagen sample was dissolved in heated water, and the higher the temperature, the lower the viscosity value. Heating can also damage the hydrogen bonds in collagen, so the collagen solution becomes diluted.

\section{Formation of derivative compounds}

The derivatizing agent used was FMOC-Cl because it can react with both the primary and secondary amino acids to form a fluorescent compound product. The derivatization reaction between the amino acids and FMOC-Cl is a substitution reaction, i.e., the $\mathrm{Cl}$ group in FMOC-Cl is replaced by the primary and secondary amine groups. The derivatization process with FMOC-Cl also requires a buffer with an alkaline $\mathrm{pH}$ of $\geq 8.0$. The collagen standard itself has a $\mathrm{pH}$ ranging from 6.5 to 8 , and the collagen assay solution is dissolved in acetate buffer ( $\mathrm{pH} 4.2)$; therefore, before being analyzed by the KCKCT method, the standard collagen solution is supplemented with a pH 9 boric buffer [8].

To select the FMOC-Cl reagent volume used, a stoichiometric calculation was performed to determine how many volumes of reagent were required to produce the optimum compound derivative. In this study, $300 \mathrm{~mL}$ of collagen test solution was used with $300 \mathrm{~mL}$ of boric buffer and $300 \mathrm{~mL}$ of FMOC-Cl.

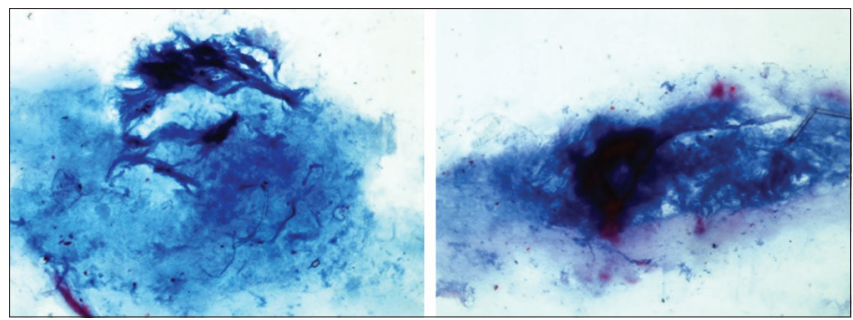

Fig. 2: Staining of bovine collagen samples with Casson's trichrome

Table 1: Hydrolysis time versus peak area of the derivatized compound

\begin{tabular}{llll}
\hline Hydrolysis time (h) & \multicolumn{2}{l}{ Peak area $(\mathbf{m V} / \mathbf{s})$} \\
\cline { 2 - 4 } & Hydroxyproline & Glycine & Proline \\
\hline 22 & 94073 & 203781 & 365141 \\
23 & 57014 & 156464 & 201178 \\
24 & 63202 & 238078 & 141636 \\
25 & 24087 & 155995 & 80549 \\
\hline
\end{tabular}

\section{Hydrolysis time optimization}

The hydrolysis of the collagen was performed with deamination to remove amine groups from amino acid compounds to break the peptide bond using $6 \mathrm{~N} \mathrm{HCl}$ at $110^{\circ} \mathrm{C}$ in an oven and was performed at the different hydrolysis times of $22,23,24$, and $25 \mathrm{~h}$. An hydrolysis of $>24$ h provided a larger glycine peak area than those of proline and hydroxyproline, as found by Schrieber and Gareis [9]. The peak areas for the hydrolysis times of 22, 23, and $25 \mathrm{~h}$ were not larger than that at the hydrolysis time of $24 \mathrm{~h}$ (Table 1 ). Thus, the optimal hydrolysis time was $24 \mathrm{~h}$.

\section{Wavelength analysis}

The optimum wavelengths for the collagen compounds for fluorescence analysis were $265 \mathrm{~nm}$ for excitation and $320 \mathrm{~nm}$ for emission (Table 2). The result showed the uptake of $0.2018 \mathrm{~A}$ and the maximum wavelength was $265 \mathrm{~nm}$.

\section{Optimum analysis conditions}

The mobile phase selected for the analysis of amino acids in the collagen samples consisted of acetate buffer: acetonitrile at a ratio of 55:45. At a mobile phase ratio of 60:40, glycine appeared at a retention time of $6.464 \mathrm{~min}$, whereas hydroxyproline and proline were not detected. At a mobile phase ratio of $65: 35$, none of the amino acids were detected. This was because the mobile phases with ratios of 60:40 and 65:35 were more polar than that with a ratio of 55:45 because of the higher aqueous acetate buffer percentages; therefore, the amino acids had a greater affinity for the stationary phase (C18 column) and a lower affinity for the mobile phase; hence, glycine, proline, and hydroxyproline had longer retention times or may not have been eluted in the 60:40 and 65:35 mobile phase ratios (more polar than the 55:45 ratio).

After the optimum HPLC conditions were determined, the flow rate was optimized by evaluating three rates: $0.8,1.0$, and $1.2 \mathrm{~mL} / \mathrm{min}$. The flow rate of $0.8 \mathrm{~mL} / \mathrm{min}$ was selected because it provided better column efficiency (small height equivalent to a theoretical plate [HETP]), a larger number of theoretical plates, and gave good separation because the resolution values between pairs of amino acids were $>1.5$.

\section{System conformity test}

The data obtained from an average of six injections of the standard collagen solution were used. The following results for hydroxyproline were obtained: Average follow-up factor, 0.918; HETP, $2.27 \times 10^{2}$; resolution, 3.475; number of theoretical plates, 11,025.67; and coefficient of variation, $0.88 \%$. The following results for glycine were obtained: Mean follow-up factor, 1741; HETP, $7.91 \times 10^{-3}$; resolution, 5213; number of theoretical plates, 31,660.617; and coefficient of variation, $0.49 \%$. The following results for proline were obtained: Mean follow-up factor 0.888; HETP $2.29 \times 10^{-2}$; resolution 4962; number of theoretical plates 10,951.5; and coefficient of variation, $1.40 \%$. The results obtained from the system conformity test data satisfied the requirements because the coefficients of variation were $\leq 2 \%$, the column efficiencies were good with small HETP values, the numbers of theoretical plates were high, and the resolution values were $>1.5$.

\section{Calibration curve and linearity test}

The linear regression gave the following equations for the calibration curve lines: For glycine, $y=9351.2 x+30.431$; for proline, $y=5824.4 x+38.859$; and for hydroxyproline, $y=1655.4 x+26.980$. The linearity tests gave a correlation coefficient (r) $=0.9979$ for glycine, $r=0.9985$ for proline, and $r=0.9981$ for hydroxyproline. The three

Table 2: Peak areas of the derivatized compound versus wavelength

\begin{tabular}{|c|c|c|c|c|}
\hline \multicolumn{2}{|l|}{ Wavelength } & \multicolumn{3}{|l|}{ Peak area $(\mathrm{mV} / \mathrm{s})$} \\
\hline Excitation (nm) & Emissions (nm) & Hydroxyproline & Glycine & Proline \\
\hline \multirow[t]{2}{*}{265} & 320 & 63202 & 238078 & 141636 \\
\hline & 330 & - & 14817 & 3902 \\
\hline
\end{tabular}


correlation coefficients $(r)$ were not $\geq 0.999$ possibly because the calibration curve solution contained all three amino acids or because of the effect of the derivatization process.

\section{Determination of the LOD and LOQ}

The LOD and LOQ values were, respectively, 0.990 and $3.301 \mu \mathrm{g} / \mathrm{mL}$ for glycine, 0.998 and $3.327 \mu \mathrm{g} / \mathrm{mL}$ for proline, and 0.900 and 3.001 $\mu \mathrm{g} / \mathrm{mL}$ for hydroxyproline. The LOQ values for the three amino acids were not within the concentration range of the calibration curve. It is possibly happen because, at the time, the calibration curve solutions were prepared they consisted of a mixture of the three amino acids; therefore, the LOD calculation and LOQ results were influenced by the linearity test and calibration curve.

Determination of glycine, proline, and hydroxyproline concentrations in collagen samples isolated from bovine tendons The percentages were calculated according to the linear regression equation of each amino acid. The mean percentages of glycine, proline, and hydroxyproline were $33.247 \pm 0.20 \% ; 11.867 \pm 0.20 \%$; and $10.510 \pm 0.23 \%$, which were similar to the levels of bovine collagen reported by Schrieber and Gareis, i.e., 33\% glycine, 11\% proline, and $10 \%$ hydroxyproline $[9,10]$.

\section{CONCLUSION}

The collagen isolated from bovine tendon was obtained at a yield of $0.690 \%$, and the identity was confirmed by FTIR functional group analysis and Casson's trichrome staining. The HPLC conditions using a fluorescence detector for analysis of glycine, proline, and hydroxyproline concentrations in the bovine tendon collagen were optimized. The analysis of amino acids gave average levels of $33.247 \pm 0.20 \%$ for glycine, $11.867 \pm 0.20 \%$ for proline, and $10.51 \pm 0.23 \%$ for hydroxyproline.

\section{CONFLICTS OF INTEREST}

All authors have none to declare.

\section{REFERENCES}

1. Silvipriya K, Kumar K, Bhat A, Kumar B, John A, Lakshmanan P. Collagen: Animal sources and biomedical application. J Appl Pharm Sci 2015;5:123-7.

2. Schmidt MM, Dornelles RC, Mello RO, Kubota EH, Mazutti MA, Kempka AP, et al. Collagen extraction process. Int Food Res J 2016;23:913-22.

3. Tridhar, NA. Collagen Production Comparation from Scales and Bone Fish Gurami (Osphronemus gourami) by Chemical and Enzyme. Bandung: Universitas Pasundan; 2016.

4. Lestari, T. Isolation and Charaterization of Collagen from Tuna Bone Fish (Thunnus albacares) as Raw Material for Pharmacy Industry. Depok: Thesis of Faculty of Pharmacy, Universitas Indonesia; 2007.

5. Association of Official Analytical Chemists. Official Methods of Analysis of AOAC International. 18 $8^{\text {th }}$ ed. Maryland: Association of Official Analytical Chemists Int.; 2005.

6. Kong J, Yu S. Fourier transform infrared spectroscopic analysis of protein secondary structures. Acta Biochim Biophys Sin (Shanghai) 2007;39:549-59.

7. National Standardization Agency. Crude Collagen from Fish ScalesQuality and Preparation Requirement. Jakarta: Badan Standardisasi Nasional; 2014.

8. Fakhri S, Mohammadi B, Jalili R, Hajialyani M, Bahrami G. Screening and confirmation of different synthetic adulterants in slimming products. Asian J Pharm Clin Res 2018;11:260-4

9. Schrieber R, Gareis H. Gelatine Handbook: Theory and Industrial Practice. Weinheim: Wiley-VCH Verlag GmbH and Co., KgaA.; 2007.

10. Khalaf FH, Salih SI. Clinical and histopathological evaluation of using platelet-rich plasma and platelet-rich fibrin matrix in treatment of induced chronic open wounds in bucks. Asian J Pharm Clin Res 2018;11:337-41. 